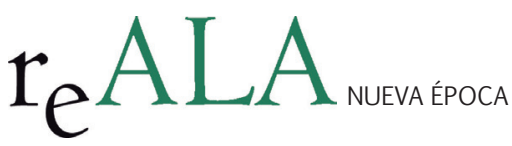

REALA, n Extraordinario, enero 2015 ISSN: 1989-8975

DOI: http://dx.doi.org/10.24965/reala.voiExtra.10222

\title{
La fusión de municipios, único instrumento de la Ley 27/2013, de 27 de diciembre, de racionalización y sostenibilidad de la Administración Local para la modificación de la planta municipal: una oportunidad perdida
}

\author{
Antonio Calonge Velázquez \\ Profesor Titular de Derecho Administrativo. Universidad de Valladolid \\ antonio.calonge@ccyl.es
}

\section{Resumen}

La Ley 27/2013, de 27 de diciembre, de Racionalización y Sostenibilidad de la Administración Local, contempla, casi como única medida, para modificar nuestra planta municipal la fusión de municipios y, para ello, crea un instrumento nuevo que es el convenio de fusión. En este trabajo, después de exponer nuestra planta municipal -también desde el punto de vista histórico-y lo realizado en otros países de nuestro entorno, se estudian las escasas previsiones que la Ley dedica a la fusión de municipios y al nuevo instrumento creado para favorecer esta política. Un año después de su entrada en vigor no se ha firmado ningún convenio de fusión y nuestra planta municipal permanece inalterable y sin expectativa de la modificación urgente y de fondo que necesita.

Palabras clave

Administración local, planta municipal, municipios, fusión de municipios, convenio de fusión.

\section{The merger of municipalities, only instrument of Law 27/2013, of December 27, rationalization and sustainability of local government to amend the municipal plant: a missed opportunity}

\section{Abstract}

The Law 27/2013, of December $27^{\text {th }}$, for the Rationalization and Sustainability of the Local Administration, takes into consideration, almost as its only measure, the merge of municipalities in order to change our municipal plant. This paper, after explaining the main features of our municipal plant (also from an historical point of view) and taking into account the achievements made by States from our nearby environment, is aimed to the study of the scarce legal provisions in the Law devoted to the merge of municipalities as well as the new instrument created to boost this policy. Not a single merge agreement has been signed one year after the Law entered into force, at the same time our municipal plant remains unalterable and without any prospect for the deep and urgent amendment that it requires.

Keywords

Local administration, municipal plant, towns, merge of municipalities, merge agreement. 


\section{SUMARIO}

1. INTRODUCCIÓN. 2. UNOS POCOS DATOS ACERCA DE NUESTRA PLANTA MUNICIPAL A LO LARGO DE LOS ÚLTIMOS TRES SIGLOS. 3. UNA RADIOGRAFÍA DE LA PLANTA MUNICIPAL ACTUAL. 4. LA SITUACIÓN EN NUESTROS PAÍSES MÁS PRÓXIMOS. 5. LA LEY 27/2013, DE 27 DE DICIEMBRE, DE RACIONALIZACIÓN Y SOSTENIBILIDAD DE LA ADMINISTRACIÓN LOCAL. 5.1. Breves consideraciones generales. 5.2. El nuevo artículo 13 LRBRL única vía para la modificación de la planta municipal. 6. EL HACER DE OTRAS COMUNIDADES AUTÓNOMAS: EL CASO DE CASTILLA Y LEÓN. 7. OTRA OPORTUNIDAD PERDIDA. 8. BIBLIOGRAFÍA

\section{INTRODUCCIÓN}

La planta local es, sin duda, un clásico de nuestro Derecho Local. El problema -mas concreto- de la planta municipal en nuestro país aparece, casi, con la formación de los Ayuntamientos constitucionales al promulgarse la Constitución de 1812 siguiendo, como en otros países de la Europa continental, el criterio francés de erigir en municipio cualquier "ville, bourg, paroisse, ou communauté de champagne". El texto constitucional gaditano disponía en su artículo 310 que "Se pondrá Ayuntamiento en los pueblos que no lo tengan y en que convenga que los haya, no pudiendo dejar de haberlo en los que por sí o en su comarca lleguen a 1000 almas, y también se les señalará término correspondiente", esbozando, después, en el Decreto CLXIII, de 23 de mayo de 1812, un procedimiento para la adquisición de la calidad de Ayuntamiento, que hacía equivalente núcleo de población y municipio-Ayuntamiento'. Es bien cierto, como nos ha recordado recientemente COSCULLUELA MUNTANER², que la Constitución de Cádiz no quiso que se produjera la creación de municipios que resultaran inviables económica y administrativamente, cual ocurriría si se crearan por debajo de la cifra indicada de 1000 almas. Sin embargo, las presiones políticas, que veremos aparecer siempre que se trate de reformas del régimen municipal³, obligaron a las Cortes Generales a aprobar un Decreto de 12 de mayo de 1812 y otros posteriores que permitieron la creación de municipios con número inferior de vecinos.

El dimensionamiento municipal de España ha sido, casi desde siempre, un debate recurrente, pero sin soluciones Un somero repaso a las sucesivas leyes de régimen local de los últimos dos siglos nos permitiría observar que todas ellas, con mayor o menor extensión, se refieren a este problema de la planta municipal ${ }^{4}$. Y, asimismo -y ello es más importante-, que realmente nunca se ha querido abordar el problema en profundidad y con ganas de solucionarlo. Es más, casi todas las leyes de régimen local han comenzado estableciendo el principio de conservación de los municipios existentes ${ }^{5}$ para regular, a continuación, la creación, supresión y lo que, tradicionalmente, se ha conocido con la denominación de alteración de términos municipales. No ha habido, pues -como denunciaran SOSA WAGNER y DE MIGUEL GARCÍA hace más de dos décadas6- una política propiamente dicha sobre esta materia, sino únicamente una serie de medidas concretas para hacer frente a las cuestiones que en este campo la realidad cotidiana presentaba en cada momento. La Ley 27/2013, de 27 de diciembre, de Racionalización y Sostenibilidad de la Administración Local (en adelante, LRSAL), que es consecuencia de la crisis económica que venimos padeciendo desde hace, al menos, siete años o, si se prefiere, un instrumento para llevar a cabo las reformas estructurales necesarias que nos permitan salir de esta crisis, sigue, a nuestro juicio, las mismas líneas que las leyes de régimen local anteriores y la denuncia formulada por los autores citados en último lugar sigue siendo plenamente válida.

1 Debe ponerse de relieve que no todos los autores participan de esta idea. Así, BARRANCO VELA, Rafael (1993): 56, sitúa -no sin cierta razón- el origen o, mejor expresado, el impulso a la proliferación municipal en la Constitución de 1845, cuyo artículo 73 disponía que "habrá en los pueblos Alcaldes y Ayuntamientos. En la Ley de organización y atribuciones de los Ayuntamientos de 8 de enero de 1845 y en la precedente de 14 de julo de 1840 encuentra el autor citado el fundamento a la posterior dispersión municipal, ya que, entre otras cosas, hasta entonces -escribe- no se puede hablar con propiedad de municipios.

2 COSCULLUELA MONTANER, Luis (2013): 12.

3 Compartimos esta afirmación que nosotros mismo hemos constatado cuando hemos estudiado la cuestión de la elección y destitución del Alcalde. CALONGE VELÁZQUEZ, Antonio y GONZÁLEZ DEL TESO, Teodosio (1995): 13-78.

4 Para un conocimiento en profundidad de esta legislación remitimos a los trabajos de SOSA WAGNER, Francisco y DE MIGUEL GARCíA, Pedro (1987): 15-55, ESCUIN PALOP, Vicente (1998) 1161-1169, BARRANCO VELA (1993): $39-99$.

5 Así, se expresaban, por sólo citar algunas, el Real decreto de 23 de julio de 1835, para el arreglo provisional de los Ayuntamientos del Reino; las leyes de organización y atribuciones de los Ayuntamientos de 1840 y 1845 , la Ley de Ayuntamientos de julio de 1856 o, también la Ley municipal de 31 de octubre de 1935 que reconocía a todos los municipios que existiesen a su promulgación.

Sólo el Real decreto de 21 de octubre de 1866 pretendió realmente la supresión de Ayuntamientos, al ordenarse que en un plazo de dos años deberían desaparecer todos los distritos municipales que no llegasen a 200 vecinos, dictándose, poco después, una real orden que trató de poner en práctica este mandato.

6 SOSA WAGNER, F. y DE MIGUEL GARCÍA, P. (1987): 41. 
En efecto, la LRSAL, como era de esperar, procedió a intervenir en el tema que nos ocupa modificando el artículo 13 de la Ley 7/1985, de 2 de abril, reguladora de las Bases del Régimen Local, que es el precepto que regula la creación y supresión de municipios, aunque, ahora, claramente -y constituye un importante cambio de tendenciatiene por finalidad principal la supresión de municipios, aunque sólo sea porque la mayor parte de su contenido está dedicado a fomentar la fusión de municipios, poniendo cortapisas a la creación de nuevos municipios y, desde luego, ya no parte per se del principio de conservación de los municipios, como hemos señalado ha hecho muchas veces nuestra legislación local.

En las páginas que siguen vamos, pues, a estudiar la planta municipal después de la promulgación hace un año de la LRSAL.

\section{UNOS POCOS DATOS ACERCA DE NUESTRA PLANTA MUNICIPAL A LO LARGO DE LOS ÚLTIMOS TRES SIGLOS}

Desde que en Cádiz se crearán tantos Ayuntamientos como pueblos, el número de municipios en España ha variado de manera considerable ${ }^{7}$. Desde que tenemos conocimientos fiables, hemos pasado de aproximadamente 11500 municipios existentes en 1842, teniendo en cuenta la indefinición jurídica de lo que era un municipio, hasta los actuales 8112, según el documento del Ministerio de Hacienda y Administraciones Públicas titulado Variaciones de los municipios de España desde 1842 (http://www.seap.minhap.gob.es/dms/es/publicaciones/centro de publicaciones_de_la_sgt/Monografiaso/parrafo/011113/text_es_files/Variaciones-INTERNET.pdf, visitado el día 27 de septiembre de 2014). Más de cuatro mil extinciones de municipios se han producido desde la fecha señalada en el estudio hasta la actualidad, de ellas 2247 entre esa fecha y 1857, es decir, en un período de tan solo quince años con la Ley de Organización y Atribuciones de los Ayuntamientos de 8 de enero de 1845 como norma habilitante. Desde que se promulgara la Ley Orgánica Municipal de 20 de agosto de 1870 en la que, como es conocido, se definen los caracteres esenciales del municipio: territorio, población y organización, hasta hoy la reducción es también importante. Para 1877 se puede estimar en 9287 municipios, aunque a principios del pasado siglo el número de municipios sólo había disminuido en veinte, esto es, el proceso de desapariciones, fusiones y agregaciones es escasamente significativo en el último tercio del siglo XIX, línea que se mantendrá hasta la década de los sesenta del siglo pasado.

En la década citada, se dictará una legislación (la Ley 48/1966) que favorecerá la fusión de municipios, produciéndose otra importante reducción hasta alcanzar los 8048 municipios que se registran el mismo año en que se promulgó la vigente Constitución que descienden a 8022 tan solo dos años después, según datos de Estudio sobre el Registro de Entidades Locales (http://www.seap.minhap.es/dms/es/areas/politica_local/sistema de informacion_local_-SIL-/registro_eell/publicaciones/parrafo/06/Estudio-Registro-Entidades-Locales-INTERNET-1-.pdf, visitado el día 30 de septiembre de 2014), aunque después se producirá un repunte en el número de municipios hasta alcanzar los 8118 que contiene el Registro de Entidades Locales a 1 de enero de 2013 (http://ssweb.seap. minhap.es/REL/, visitado el día 30 de septiembre de 2014). Entre 1980 y 2013, 99 nuevos ayuntamientos (el último ha sido el año pasado, el de Valderrubio en la provincia de Granada) se han incorporada a la ya larguísima lista de municipios españoles.

Como observamos, no sólo no se ha llevado a cabo ningún intento serio, en nuestra opinión, de modificación de esta situación, sino que el número de municipios ha ido aumentando desde que se aprobara la vigente Constitución y la posterior legislación de régimen local de desarrollo.

\section{UNA RADIOGRAFÍA DE LA PLANTA MUNICIPAL ACTUAL}

Como acabamos de indicar, son 8118 los municipios que existen en España en el momento de escribir estas líneas. De éstos sólo 400 municipios, que representan el 5\% del total, superan los 20000 habitantes y, de ellos, 145 cuentan con una población superior a 50000 habitantes que si excluimos las capitales de provincia, tan sólo serían 93 los que superan la cifra antedicha. Por el contrario, el 60,45\% tiene una población inferior a 1000 habitantes o, si se prefiere, seis de cada diez, y de éstos, 3796 están poblados por menos de 500 habitantes. Nuestra administración municipal es, a la vista de estos pocos datos, una "administración municipal rural"

Sin duda, nuestra planta municipal puede ser calificada de inframunicipal o, como ha explicitado FERNÁNDEZ RODRÍGUEZ, nos encontramos ante la farsa de más de 8000 Administraciones públicas", ante "apariencias jurí-

7 Un análisis de la evolución del mapa municipal se puede ver en ORDUÑA REBOLLO, Enrique (2003): 779-

8 CARRILLO BARROSO, Ernesto (1986): 293.

9 FERNANDEZ, RODRÍGUEZ, Tomás Ramón (1987): 23. 
dicas sin sustantividad social alguna", "ante municipios carentes de capacidad y sustantividad por sus escasas e ínfimas dimensiones" ", que no cumplen con la doble razón de ser de este tipo de Entidades: democrática, en tanto que son el cauce inmediato de participación de los ciudadanos y precisamente en aquellos asuntos que más directamente conciernen a la vida diaria; y de eficacia administrativa, en tanto que son el ámbito de prestación de los servicios públicos condicionantes y determinantes de dicha calidad de vida. En definitiva, ante municipios en los que el principio de autonomía proclamado en el artículo 137 de la Constitución no deja de ser una mera apariencia por la escasez de medios materiales y personales con que cuentan para cumplir las funciones que tienen encomendadas. "La autonomía municipal -escribíamos en 2001-, a pesar de su reconocimiento y garantía institucional, sólo puede ser ejercitada -o, si se quiere, disfrutada- por unos pocos municipios; a los demás el peso de la púrpura no les permite sostenerse en pie" ${ }^{11}$.

Además, hemos incidido, como hemos puesto de relieve, en el problema desde que fue aprobada la vigente Constitución. Es más, ya con la crisis económica que padecemos iniciada hemos continuado creando administraciones públicas, segregando municipios. Pinar del Río, La Canonja, Villanueva de la Concepción, Vegaviana, Alagón del Río, Guadiana del Caudillo y Valderrubio son las últimas segregaciones municipales. En sentido contrario, sólo una fusión de municipios se ha llevado a cabo, la de Oza-Cesuras que tuvo lugar en junio de 2013 cuando hacía cuarenta y cinco años que no se realizaba ninguna operación de este tipo (la última fue la que tuvo lugar en 1981 cuando se fusionaron los municipios burgaleses de Rio Losa y San Martín.

La ratio de población por municipio es de 5754 habitantes y debe recordarse que 5000 es el número mínimo de habitantes que contempla la LRBRL cuando hace referencia a las obligaciones mínimas de los municipios. Según el último padrón municipal publicado por el Instituto Nacional de Estadística (http://www.ine.es/jaxi/menu. do?type=pcaxis\&path=\%2Ft20\%2Fe260\&file=inebase\&L=0 visitado el día 1 de octubre de 2014) 5187 municipios (el $63 \%$ ) han perdido población desde que comenzara la crisis.

Ahora bien, todos estos datos son o absolutos o la media de España, pero el problema de la planta municipal no afecta por igual a todas las Comunidades Autónomas.

En Castilla y León, desde donde se escriben estas páginas, el problema es catastrófico. Castilla y León está integrada por 2248 municipios, lo que hace que ocupe, en cuanto al número de municipios, el primer puesto de todas las Comunidades Autónomas, Pero es que, además, el 86,81\% de estos municipios tiene una población inferior a 1000 habitantes (1953), y hasta un 73,1\% su población es inferior a 500 habitantes (1639). En cifras absolutas debemos señalar que 1957 municipios tienen menos de 1000 habitantes y 1657 tiene, aún, menos de 500 habitantes, lo que representa el $45 \%$ de los municipios españoles. Sólo 48 municipios tienen más de 5000 habitantes, de los que 14 superan los 20000 habitantes,. Y, por último, pongamos de relieve que sólo son 4 los municipios castellanos y leoneses que superan los 100000 habitantes: Burgos, León, Salamanca y Valladolid. Castilla y León, podemos afirmar, está integrada de manera muy mayoritaria por inframunicipios. De "verdaderas administraciones fantasmas" han sido calificados muchos municipios de Castilla y León ${ }^{12}$.

La ratio de población por municipio es de 1121 habitantes. Con una población muy dispersa, la mayoría de los habitantes se concentran en los 48 municipios que cuentan con más de 5000 habitantes. En éstos, residen 1.621.816 habitantes; de los 2.519.875 habitantes que, según la renovación municipal de habitantes de 2013, dispone Castilla y León: viviendo 768940 personas en los 4 municipios con más de 100000 habitantes.

Por provincias la situación es, también, desigual. Burgos, con 371 municipios, y Salamanca, con 362, son las provincias con mayor número de municipios, seguidas de Ávila y Zamora, con 248 municipios, teniendo la mayoría de éstos menos de 1000 habitantes.

A los datos precedentes, debemos añadir que la Comunidad Autónoma de Castilla y León es, también, la que cuenta con mayor número de Entidades de Ámbito inferior al municipio de toda España. De las 3716 Entidades de ámbito territorial inferior al municipal que, según el censo de Entidades Locales ( http://ssweb.seap.minhap.es/ REL/ visitado el día 3 de octubre de 2013), existen en nuestro país, 2225 están ubicadas en Castilla y León, concentrándose la mayor parte de ellas en la provincia de León (1232).

Ahora bien, pese a lo dicho hasta ahora, coincidimos con REBOLLO PUIG, en que "no cabe achacar sólo a los municipios de escasa población la sobreabundancia estéril y nociva ni es razonable limitar a ellos la reducción del número total. Más absurdo que la existencia de municipios con pocos vecinos pero muy aislados es la de aquellos que, aunque grandes, han llegado a confundirse físicamente pero que mantienen incólumes sus ayuntamientos y toda la estructura organizativa y que se resisten a cualquier fusión con argumentos endebles"13.

10 Son expresiones de FANLO LORA, Antonio (1995): 176 y (1996): 241.

CALONGE VELÁZQUEZ, Antonio (2001): 138.

LÓPEZ ANDUEZA, Isaías (1997): 46.

13 REBOLLO PUIG, Manuel (2012): 208-209.

REALA, n Extraordinario, enero 2015, ISSN: 1989-8975 - DOI: http://dx.doi.org/10.24965/reala.v0iExtra.10222 


\section{LA SITUACIÓN EN NUESTROS PAÍSES MÁS PRÓXIMOS}

Mientras en España, como hemos señalado, no hemos ofrecido ninguna solución al problema del dimensionamiento municipal e, incluso, según hemos puesto de relieve, hemos seguido creando administraciones públicas durante los años que llevamos de crisis económica, otros países europeos han realizado hasta drásticas reformas en su estructura local bastantes años antes - incluso- de la actual crisis.

En Europa, diversas reformas territoriales se pusieron en marcha para disminuir el número de municipios con los argumentos de prestar mejor los servicios públicos y disminuir los gastos locales.

En este sentido, destacan la República federal de Alemania que entre los años 1967 y 1978 pasó de alrededor de 24000 municipios, de los cuales 10760 tenían menos de 500 habitantes, a 8505 (después de la unificación se sumaron casi 4000 más). Bélgica, que tenía 2669 municipios a principios de la mitad del pasado siglo, cuenta con 589 desde 1992, agrupados en cinco provincias en cada una de las dos regiones más la región de Bruselas-capital, es decir, redujo sus municipios en un 78\%. Dinamarca, también en el mismo periodo pasó de 1387 municipios a tan sólo 275 , lo que representa un $80 \%$. Suiza, también desde hace varios años, viene intentando reducir el número de municipios, y de los 3021 que tenía a principios de los noventa ha pasado a 2495 en 2012. Suecia disminuyó en el $87 \%$ el número de municipios pasando en el período a que nos venimos refiriendo de 2281 a 286 tan sólo. Y, por último, el Reino Unido, por citar un ejemplo más, redujo en 1544 municipios los 2028 que contaba en la década de los cincuenta del siglo pasado.

Como se puede concluir, las reducciones más importantes se operaron en los países del norte de Europa y, de ahí, que todos los ejemplos que acabamos de exponer, se refieran a países de ese entorno geográfico. Los países del sur, por el contrario, en el mismo período de tiempo o bien redujeron de manera poco significativa su planta municipal (Grecia pasó de 5959 municipios a 5922 o España que de 9214 pasamos a 8022) o, incluso la incrementaron como es el caso de Italia que de 7781 pasó 8100 municipios o Portugal que tenía 303 municipios y aumentó en dos más.

Ya durante la crisis económica, Dinamarca, en 2007, volvió a reducir sus municipios quedándose con 98 agrupados en cinco regiones al establecer como criterio la cifra mínimo de 20000 habitantes para conformar municipio. Finlandia, en 2006, mediante el programa PARAS ha reducido sus municipalidades de 431 a 320 en 2013 , y tienen prevista para 2017 una nueva reforma municipal. Grecia, desde el 1 de enero 2011, a través del llamado Plan Kallikatris, ha pasado de estar conformada por 1034 municipios a 325 en unas ocasiones a través de agrupaciones voluntarias y en otras forzosas. Hungría ha establecido como criterio mínimo para la existencia de municipios el número de 2000 habitantes. Islandia ha reducido su mapa municipal a tan sólo 74 municipios de los aproximadamente 7000 con que contaba en la década de los noventa. Letonia, con una importante reforma territorial que entró en vigor el 1 de julio de 2009, pasó a tener 110 municipios de los 586 con que se organizaba antes de la reforma señalada. Por último, nuestros vecinos portugueses, tras una importante reforma llevada a cabo en 2012 inspirada en las recomendaciones de la Troika, ha hecho desparecer 1500 parroquias de las 4259 que tenía antes de la reforma.

Francia, que es el país con más municipios de Europa (36682, entre los que están 114 de ultramar), recientemente, también se ha sumado a esta ola de fusiones y en un proyecto de ley presentado por el presidente Hollande contempla la integración de municipios de menos de 20000 habitantes.

Desde luego, no es la fusión o agrupación de municipios la única medida adoptada por los países europeos para hacer frente a la crisis económica, aunque sí se encuentra entre las que están adoptando los distintos Estados según su ordenamiento constitucional'14.

\section{LA LEY 27/2013, DE 27 DE DICIEMBRE, DE RACIONALIZACIÓN Y SOSTENIBILIDAD DE LA ADMINISTRACIÓN LOCAL}

\subsection{Breves consideraciones generales}

España no se ha mantenido al margen, lógicamente, de la ola de reformas obligada por la crisis económica. La LRSAL se enmarca, según indicamos en las primeras páginas de este trabajo, en este contexto como refleja su

14 Un completo examen de esta cuestión se puede ver en el Informe del Consejo de Municipios y Regiones de Europa, La descentralización en el cruce de caminos. Reformas territoriales en Europa en período de crisis, en el sitio internet http://ccre.org/img/uploads/piecesjointe/ filename/CCRE_broch_FR_complet_low.pdf (visitado el 6 de octubre de 2014) 
propio título, según ha advertido de manera acertada ALONSO MAS ${ }^{15}$. En efecto, la Ley señalada busca ante todo garantizar la sostenibilidad y el equilibro presupuestario de los Entes locales. Son los principios que inspiran esta Ley para garantizar la sostenibilidad de los servicios públicos y la clarificación de las competencias locales con la finalidad de evitar duplicidades con las competencias de otras Administraciones; a los que deben añadirse dos objetivos más: racionalizar la estructura organizativa y favorecer una regulación que fomente la iniciativa privada evitando intervenciones administrativas desproporcionadas.

La LRSAL no es, advirtámoslo, una reforma parcial de la Administración local, sino, a nuestro juicio, una reforma en profundidad de ésta, a través de la modificación de numerosos preceptos de la LRBRL y alguno de la Ley de Haciendas Locales, que hará que cambie el concepto de gobierno local que hoy tenemos.

Ahora bien, en la acotada parcela que nos corresponde en este estudio, la LRSAL sólo incorpora como novedad, en nuestra opinión, que por primera vez se introducen medidas concretas para fomentar la fusión voluntaria de municipios; e introduce un nuevo procedimiento de fusión, voluntario, entre Ayuntamientos colindantes de una misma provincia mediante el denominado convenio de fusión.

Esta Ley, debe recordarse, vio la luz en el BOE de 30 de diciembre de 2013 después de un largo proceso que incluye la elaboración de varios anteproyectos de Ley y una larga y compleja tramitación parlamentaria.

En efecto, a principios de febrero de 2012, si no queremos remontarnos a otros antecedentes más remotos ${ }^{16}$, el Gobierno comenzó a elaborar los primeros borradores (hasta once borradores se han llegado a contabilizari7) y será en julio de ese mismo año cuando aprobará un anteproyecto que finalmente no vio la luz y que fue tremendamente contestado por la FEMP y por las Federaciones territoriales de municipios, así como desde los partidos políticos de la oposición. Este texto no contemplaba una modificación del artículo 13 LRBEL, sino que en la práctica venía a prever la supresión de los municipios con población inferior a 5000 habitantes y su absorción por un municipio colindante cuando la prestación en el ámbito municipal de los servicios públicos, ya sea en razón de la naturaleza del mismo, la población, o la sostenibilidad financiera no cumpliera con los estándares de calidad dispuestos en el propio texto, que remitía a un Real Decreto de desarrollo de la Ley, cuyo único parámetro que se manejaba para la determinación del coste de los servicios era la demografía (artículo primero, seis del anteproyecto de Ley para la Racionalización y Sostenibilidad de la Administración Local.)

Un nuevo anteproyecto vería la luz meses más tarde (febrero de 2013) que no difería sustancialmente del anterior y que, asimismo, fue criticado por los municipios a través de sus organizaciones representativas, pues seguían considerándolo un claro ataque contra la autonomía local y las competencias municipales. Comunidades Autónomas y partidos políticos también mostraron su oposición a este nuevo texto. El Consejo de Estado, en su dictamen 567/2013, de 26 de junio, fue muy crítico con el texto remitido por el Gobierno, concluyendo, en líneas generales, que tanto el precepto constitucional invocado como fuente de competencia del Estado era incorrecto, como advirtiendo de forma expresa la inconstitucionalidad de algunas medidas que en el mismo se contemplaban y así, por ejemplo, la regulación del coste estándar podía incidir notoriamente en el desenvolvimiento efectivo de la autonomía municipal y, a la postre, reducir en exceso el ámbito competencial que integra el núcleo esencial de esa autonomía constitucionalmente garantizada.

Finalmente, se aprobó como Proyecto un nuevo texto (BOCCGG, Congreso de los Diputados, de 6 de septiembre de 2013) que suprimió o, al menos, suavizó la regulación de los aspectos más cuestionados y, en concreto y por lo que a nosotros nos atañe, la práctica desaparición de los municipios en virtud de las medidas previstas en los textos anteriores desapareció y su sustitución por una modificación del artículo 13 LRBRL en el sentido que indicaremos a continuación, así como otras medidas que tienen que ver, sobre todo, con el ámbito competencial municipal y con el cumplimiento del objetivo de estabilidad presupuestaria, del objetivo de deuda pública o de la regla del gasto (artículo 116 bis LRBRL).

\subsection{El nuevo artículo 13 LRBRL única vía para la modificación de la planta municipal}

El Proyecto de LRSAL, como hemos indicado, introdujo modificaciones al artículo 13 LRBRL, que tiene como principales novedades: el establecimiento de medidas concretas favorecedoras de la fusión de municipios, por un lado, y, por otro, la creación de una nueva forma o instrumento para agregarse municipios, a través del llamado convenio de fusión.

15 ALONSO MAS, Ma José (2014): 297.

16 Nos referimos al Programa Nacional de Reformas, Reino de España, 2012 en el sitio internet (http://www.lamoncloa.gob.es/documents/pnrdefinitivo.pdf, visitado el día 10 de octubre de 2014) en cuyas pp.94 y ss. se señalan objetivos y medidas para racionalizar el número de entidades locales y sus competencias,

17 FLORES DOMÍNGUEZ, Luis Enrique (2013) 
Esta Ley no contiene -como sí han hecho otras a lo largo de nuestra historia- el principio de conservación de municipios, sino que pretende establecer una estructura municipal más eficiente, aunque ello lo hace a base de favorecer las fusiones, pero no sin imposiciones. La Ley, en suma, no ha optado por la supresión de municipios pequeños o financieramente inviables, sino por promover y facilitar su agrupación. Sí establece unos requisitos más exigentes para la creación de nuevos municipios; y éstos son: un mínimo de población de 5000 habitantes, sostenibles desde el punto de vista financiero, con suficientes recursos para el cumplimiento de las competencias municipales que están obligados a atender por Ley, y que se sigan prestando con los mismos estándares de calidad con las que se venían prestando. "La creación de nuevos municipios sólo podrá realizarse sobre la base de núcleos territorialmente diferenciados de al menos 5000 habitantes y siempre que los municipios sean financieramente sostenibles, cuenten con recursos suficientes para el cumplimiento de las competencias municipales y no suponga disminución de la calidad de los servicios que venían siendo prestados" (apartado $2^{\circ}$ ). El legislador estatal -y, ade-

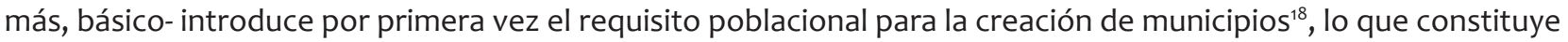
un elemento más para afirmar el cambio de modelo que significa esta Ley.

Por otro lado, el Estado, sin perjuicio de las competencias de las Comunidades Autónomas, podrá establecer las medidas que considere convenientes para la fusión de municipios, aunque con el fin de mejorar la gestión de los asuntos públicos locales, atendiendo a criterios geográficos, sociales, económicos y culturales. Es decir, el Estado también se responsabiliza o, mejor dicho, se corresponsabiliza, en el marco de su ámbito competencial, para lograr una estructura municipal más racional y eficiente (apartado 3 ).

Desde el punto de vista procedimental, el nuevo artículo 13 introduce un nuevo informe preceptivo de la Administración que ejerza la tutela financiera en el supuesto de creación o supresión de municipios, así como en el caso de la alteración de los términos municipales (apartado $1^{\circ}$ ) que será la Comunidad Autónoma correspondiente, pues es ella la competente para aprobar la alteración de los términos municipales. Sin duda, este nuevo iter procedimental está pensado para lograr el objetivo de crear sólo municipios que sean financieramente sostenibles.

Pero, la novedad más importante es, sin duda, el instrumento creado ex novo y pensado para lograr la fusión voluntaria de municipios al margen, en este caso, de la legislación de las Comunidades Autónomas que son -repetimos- las competentes en materia de alteraciones de los términos municipales comprendidos en su territorio desde que el artículo 148.1.2 ${ }^{\text {a }}$ de la Constitución posibilitó que los Estatutos de Autonomía recogieran esta competencia. La Constitución, primero, y los Estatutos de Autonomía, después, permiten, pues, responsabilizarse a las Comunidades Autónomas en gran medida del proceso de reforma y modernización de las estructuras de la organización territorial.

Sin adentrarnos en la competencia del Estado para llevar a cabo esta regulación por estar, en nuestra opinión, ya suficientemente tratada por la doctrina más reciente, en las páginas que siguen nos vamos a dedicar a exponer las escasas previsiones normativas existentes en la LRASL sobre los convenios de fusión.

El artículo 13.4 dispone que los municipios colindantes, con independencia de su población, dentro de la misma provincia, podrán acordar su fusión mediante un convenio de fusión, sin perjuicio del procedimiento previsto en la normativa autonómica. Sin establecer el contenido de este convenio, por lo que será el que voluntariamente acuerden los municipios que decidan fusionarse, el legislador se ha limitado, sobre todo, a establecer medidas que pretenden fomentar la fusión de municipios a través de este instrumento, y así:

- El coeficiente de ponderación que sea de aplicación conforme al artículo 124.1 del texto refundido de la Ley Reguladora de las Haciendas Locales (TRHL), aprobado mediante Real Decreto Legislativo 2/2004, de 5 de marzo, se incrementará en $0.10 \%$.

El esfuerzo fiscal y el inverso de la capacidad tributaria que le corresponderá en ningún caso será inferior al más elevado de los valores previos que tuviera cada uno por separado antes de la fusión, de acuerdo con el artículo 124.1 TRHL

Su financiación mínima del municipio resultante será la suma de las financiaciones mínimas que tuvieran por separado antes de la fusión, conforme al artículo 124.2 TRHL.

De la aplicación de las reglas señaladas no podrá derivarse, para cada ejercicio, un importe total superior al que resulte de lo dispuesto en el artículo $123 \mathrm{TRHL}$

Se sumarán los importes de las compensaciones que, por separado, corresponden a los municipios que se fusionen y que se derivan de la reforma del impuesto sobre Actividades Económicas (IAE) de la disposición adicional décima de la Ley 51/2002, de 27 de diciembre, de reforma de la Ley 39/1988, de 28 de diciembre, Reguladora de

18 Sobre la discusión del número municipio necesario para la creación de municipios, vid COSULLUELA MONTANER (2013). 
las Haciendas Locales, actualizadas en los mismos términos que los ingresos tributarios del Estado en cada ejercicio respecto a 2004, así como la compensación adicional, regulada en la disposición adicional segunda de la Ley 22/2005, de 18 de noviembre, actualizada en los mismos términos que los ingresos tributarios del Estado en cada ejercicio respecto a 2006.

El nuevo municipio resultante de la fusión quedará dispensado de prestar nuevos servicios mínimos de los previstos en el artículo 26 LRBRL que le corresponda por su aumento poblacional.

Durante, al menos, los cinco primeros años desde la adopción del convenio de fusión, tendrá preferencia en la asignación de planes de cooperación local, subvenciones, convenios u otros instrumentos basados en la concurrencia. Este plazo podrá prorrogarse por la Ley de Presupuestos Generales del Estado.

Desde el punto de vista procedimental, el legislador estatal no ha determinado ninguno concreto, por lo que deberá seguirse el previsto en la legislación autonómica de manera íntegra. Ahora bien, sí que ha introducido una prescripción con la finalidad de favorecer la fusión de municipios mediante la utilización de este instrumento. Me refiero a que el apartado sexto del artículo 13 exime, en estos casos, de la exigencia de la mayoría absoluta del número legal de miembros de la Corporación y la sustituye por la mayoría simple de cada uno de los plenos de los Ayuntamientos que se fusionan.

El legislador sí que establece una limitación importante o, mejor dicho, una garantía para que las fusiones de municipios que se realicen a través a este instrumento sean estables y con vocación de perdurabilidad, ya que prohíbe al nuevo municipio resultante de la fusión segregarse durante un plazo de, al menos, diez años.

La fusión así realizada produce una serie de consecuencias, que son:

En primer lugar, se dará la integración de los territorios (mejor hubiera sido decir términos municipales), poblaciones y organizaciones de los municipios, incluyendo los medios personales, materiales y económicos del municipio fusionado. El pleno de cada Corporación adoptará las mediadas de redimensionamiento para la adecuación de las estructuras organizativas, inmobiliarios, de personal y de recursos resultantes de la nueva situación, sin que pueda derivarse, en ningún caso, incremento de la masa salarial de los municipios fusionados.

Hasta las próximas elecciones locales, el órgano de gobierno del municipio fusionado estará integrado por la suma de los concejales de los municipios fusionados de acuerdo con lo previsto en la Ley Orgánica de Régimen Electoral General.

El nuevo municipio fusionado se subrogará en todos los derechos y obligaciones de los municipios fusionados, si bien si alguno de los municipios fusionados estuviera en situación de déficit sus obligaciones, bienes y derechos patrimoniales que se consideren liquidables podrán integrarse en un fondo, sin personalidad jurídica y con contabilidad separada, adscrito al nuevo municipio, que designará un liquidador al que le corresponde la liquidación de este fondo. Esta liquidación deberá llevarse a cabo en el plazo de cinco años desde la adopción del acuerdo de fusión, sin perjuicio de los posibles derechos que puedan corresponder a los acreedores.

El nuevo municipio fusionado deberá aprobar un nuevo presupuesto para el ejercicio presupuestario siguiente a la adopción del convenio de fusión

Una consecuencia más que prevé la LRSAL, desde el punto de vista organizativo, es que, con carácter potestativo y si así lo dispone el convenio de fusión, cada uno de los municipios fusionados, o alguno de ellos podrá funcionar como forma de organización desconcentrada de conformidad con lo previsto en el artículo 24 bis LRBRL.

\section{EL HACER DE OTRAS COMUNIDADES AUTÓNOMAS: EL CASO DE CASTILLA Y LEÓN}

No sólo porque estas páginas se escriben en la Comunidad Autónoma a que se hace referencia en la rúbrica, sino por la singularidad de la legislación adoptada, merece que dediquemos las siguientes páginas a conocer lo realizado en Castilla y León.

En primer lugar, debemos subrayar que la Comunidad Autónoma de Castilla y León se adelantó a lo que sería el modelo propuesto por la LRSAL mediante la Ley 7/2013, de 27 de septiembre, de Ordenación, Servicios y Gobierno del Territorio de Castilla y León (en adelante, LOSGT), a modo de lo que, como algún autor ha escrito, podría denominarse "legislación preventiva" ${ }^{19}$ de cara a evitar aquellos aspectos que pudieran ser más perjudiciales para la singularidad de Castilla y León, aunque el propio legislador autonómico consciente de la provisionalidad de

19 HEREDERO ORTIZ DE LA TABLA, Luis (2014): 7. 
alguno de los preceptos que aprobaba añadió una Disposición Final Décima que mandaba a la Junta de Castilla y León para que, en el plazo de un año, elevara a las Cortes de Castilla y León un proyecto de ley de adecuación a la legislación básica estatal si ésta pudiera suponer una modificación de la Ley que se aprobaba.

Y, en segundo término -y más relevante- con esta Ley se opta por un modelo propio y original que pretende dar respuesta a la ya conocida situación municipal de Castilla y León que tuvimos ocasión de describir en un trabajo anterior nuestro ${ }^{20}$.

En efecto, esta Ley se caracteriza por el reconocimiento de las entidades locales y por el principio de conservación de éstas, pues, como indicó el Consejero de la Presidencia en el debate a la totalidad de este proyecto de Ley, uno de sus objetivos específicos ha sido evitar la supresión de municipios o cualquier otra entidad ${ }^{21}$, y, para ello, opta por la potenciación de fórmulas de gobierno y administración más eficientes, especialmente las de carácter asociativo y voluntario, regulando las Mancomunidades de Interés General (MIG) y la fusión de municipios.

No es novedosa esta línea de actuación que ya venía siendo una constante desde que, casi a mediados de los ochenta apenas constituida la Comunidad Autónoma, se dictara el Decreto 110/1984, de 27 de septiembre, para el fomento de las Mancomunidades Municipales (BOCyL de 1 de octubre; y la Ley 1/1998, de 4 de julio, de Régimen Local de Castilla y León (en adelante, LRLCyL), volviera a optar por la fórmula del asociacionismo municipal para tratar de paliar los problemas de la ordenación municipal existente.

La LRLCyL, en su artículo 32, regula las denomina Mancomunidades de interés comunitario, a las que define como aquellas cuyo ámbito territorial concuerde sustancialmente como espacios de ordenación territorial para la prestación de servicios estatales, autonómicos o provinciales (apartado 1) y que corresponde a las llamadas Áreas Funcionales -contempladas en la Ley 10/1998, de 5 de diciembre, de Ordenación del Territorio de la Comunidad Autónoma de Castilla y León-, que constituyen ámbitos para la ordenación territorial de escala intermedia entre el nivel regional y el municipal. De este modo, las Mancomunidades podían servir como un ámbito territorial adecuado para la realización de obras y servicios por parte por parte del resto de las Administraciones públicas, al tiempo que podrán contribuir, mediante el ejercicio de la solidaridad y de la acción en común, a constituir ámbitos territoriales supramunicipales más adecuados para la gestión de las competencias municipales y que supongan la base para una alternativa a la actual organización territorial. El legislador remitía a la potestad reglamentaria de la Junta los requisitos que deberían reunir estas Mancomunidades para obtener la calificación de interés comunitario y los beneficios derivados de tal. Lamentablemente, la Junta de Castilla y León no desarrolló reglamentariamente la Ley y las potencialidades que se advertían en esta figura para avanzar en la estructura territorial municipal de nuestra Comunidad Autónoma quedaron truncadas

La LOSGT, por su parte, impulsa, como hemos señalado, un nuevo modelo de ordenación y gobierno del territorio en el que cobra mayor relevancia un tipo especial de mancomunidades que crea: las MIG, a las que concibe como un instrumento en manos de las corporaciones locales para gestionar con eficiencia los recursos municipales a través de la generación de economías de escala.

La Ley dedica el Título IV a las MIG. A través de cinco capítulos desgrana el régimen jurídico de este tipo de Mancomunidades. El precepto cabecera de este Título, el artículo 32.2, define a las MIG como entidades locales de base asociativa y carácter voluntario, con personalidad jurídica propia y capacidad de obrar plena e independiente de los municipios que la integran, para el cumplimiento de sus fines específicos. Estas mancomunidades para ser declaradas de interés general tendrán una cartera común y homogénea de competencias y funciones de entre las previstas en la normativa de régimen local. La declaración de MIG se efectuará mediante Orden de la Consejería competente en materia de Administración Local, previa acreditación del cumplimiento de los requisitos previstos en esta Ley, especificándose, de manera expresa los relativos a la materia de personal, ya que la Ley quiere evitar cualquier incremento de coste por este capítulo y, en suma, que se considere que se crea un escalón burocrático más en el conjunto de nuestras Administraciones públicas o, si se prefiere, que se crea un escalón administrativo más.

Las MIG podrán ser rurales o urbanas. Las primeras las define el artículo 37.1 LOSGT como las surgidas de la asociación voluntaria entre municipios con población inferior o igual a 20.000 habitantes, que cumplan los requisitos previstos en esta ley, sin que un municipio pueda pertenecer a más de una MIG rural. Las MIG urbanas se definen en el artículo 42.1 LOSGT como las surgidas de la asociación voluntaria de municipios con población superior a 20.000 habitantes y los municipios de su entorno o alfoz que cumplan los requisitos previstos en esta Ley, y que deberán coincidir con las áreas funcionales estables.

20 CALONGE VELÁZQUEZ, A (2001): 138-144.

21 Diario de Sesiones, Cortes de Castilla y León, $\mathrm{n}^{\circ}$ 77, de 15 de julio de 2013, pp.5257 y 5258. 
En cuanto a la fusión de municipios, la LOSGT le dedica su Título V contemplando una serie de medidas de índole económica que pretenden fomentar la fusión de municipios. Estas medidas no son sino las ya previstas en la LRLCYL (artículo 18) a las que se añade ahora una de carácter previo a la fusión para que los municipios interesados acuerden la elaboración conjunta de un plan director que tendrá por objeto la planificación y programación del proceso de fusión y la preparación de la documentación necesaria para llevarla a cabo (artículo 63.2)

La LOSGT opta con claridad, en nuestra opinión, por un modelo distinto al que establece la LRSAL, pues, por un lado, preserva a los municipios que existen y, de manera expresa, a las entidades locales menores, disponiendo en la disposición final octava que "en el marco de la legislación básica del Estado, y de acuerdo con el mandato del Estatuto de Autonomía, se regulará y garantizará el mantenimiento de las actuales entidades locales menores, y se fomentará su modernización", y, por otro, recurre a las formulas asociativas para conseguir dos finalidades: una, evitar las supresión de municipios; y, dos, mejorar la calidad de vida y el bienestar de los ciudadanos de Castilla y León prestándoles unos servicios públicos acordes a la realidad del siglo XXI.

En definitiva, a nuestro juicio, Castilla y León sigue un modelo de régimen local arraigado en el municipalismo que constituye una de sus señas de identidad.

\section{OTRA OPORTUNIDAD PERDIDA}

Nadie duda de las dificultades de reformar la planta municipal en cualquier país de que se trate. Los que han pasado por esta experiencia bien conocen los problemas, las complicaciones y los sentimientos que deben superarse para llevar a cabo una reforma lo más racional posible.

COSCULLUELA MONTANER ha sintetizado, de manera acertada, las razones de estas dificultades ${ }^{22}$ :

a) "En el plano sentimental, que por definición pugna siempre con toda idea racional, existe un sentimiento generalizado de enraizamiento con el lugar de nacimiento, que tiene carácter casi atávico, y que se manifiesta como todo sentimiento localista por dos factores: la creación de un falso enemigo exterior, que se identifica con el rechazo a los pueblos vecinos, y sobre todo a los municipios más importantes; y la defensa de un identidad natural vinculada al pueblo de origen, que se mitifica."

b) El segundo factor es político. Ligado al sentimentalismo que hemos analizado se produce un rechazo hacia todo movimiento político que defienda reformas que comporten supresión de los pequeños municipios en los que reside o se ha nacido. Rechazo que, lógicamente, tiene sus consecuencias en los procesos electorales de los países democráticos, y que juegan en contra de las fuerzas políticas que defienden la reforma a favor de las que la rechazan.

c) El tercer factor se apoya en las doctrinas que ven en el municipio una entidad natural.

Y, nosotros, añadiríamos una cuarto factor, que es la idea de libertad y, en definitiva, el derecho fundamental a residir donde se quiera y, en consecuencia, a recibir las prestaciones y servicios públicos a que tenemos derechos como ciudadanos.

Sean cuales sean los motivos, lo cierto es que ni la Ley estatal ni la ley autonómica abordan la necesaria y urgente reforma del mapa municipal para evitar lo que, en otro lugar, hemos denominado "inframunicipios", que son entidades "carentes de capacidad y sustantividad en las que los principios constitucionales de autonomía y suficiencia financiera están bastante alejados de la realidad"23.

La LRSAL porque contempla sólo medidas de incentivación económica y un nuevo instrumento jurídico para modificar una realidad y procurar otro mapa municipal mediante la fusión de municipios. Unas medidas que ya han sido adoptadas en otros momentos de nuestra historia local y que apenas han conducido a los resultados buscados. Prueba de lo que decimos es que, al año de aprobación de esta nueva Ley local del Estado, no tenemos conocimiento de que se haya firmado algún convenio de fusión, ni de que se haya iniciado la elaboración de ninguno. De tal manera que si la última fusión de municipios la tuvimos cuarenta y cinco años después de que se realizara la anterior, fácilmente transcurrirá un período similar antes de que se produzca otra.

El legislador estatal, pues, en nuestra opinión, no ha tenido la valentía necesaria que se debe exigir a todo aquel quiere modificar la realidad estéril que le circunda.

Por otro lado, la Ley autonómica (la LOSGT) tampoco se ha caracterizado por intentar modificar la realidad municipal; antes, al contrario, como hemos visto, ha optado por la conservación y mantenimiento de municipios y entidades locales menores. Ha optado, como viene haciendo desde hace años con escasos resultados, por las

22 COSCULLUELA MONTANER, L. (2012): 37.

23 CALONGE VELÁZQUEZ, A. (2008): 
asociaciones de municipios para una gestión común de obras y servicios municipales. Las mancomunidades de municipios sin o con el apellido que se las quiera poner (de interés comunitario o de interés general) ni son una fórmula nueva, ni siempre responden -más bien casi nunca- a unas mínimas exigencias de eficiencia y eficacia.

En consecuencia, Estado y Comunidades Autónomas (al menos desde la que se escriben estas páginas) han perdido otra oportunidad, a nuestro juicio, de cambiar radicalmente el mapa municipal orientándose a construir auténticas administraciones prestadoras de los servicios que demandan los ciudadanos del presente siglo.

Un argumento que muchos utilizan para oponerse a una reforma radical es la idea del municipalismo, pero lo identifican con la conservación de los municipios y, por ello, desde la propia FEMP, se consideró que una “línea roja" era la supresión de municipios, esto es, que la reforma legislativa no debía de ir acompañada de ninguna medida que supusiera la desaparición de este tipo de entidades locales y, en general, de ninguna otra. A mi juicio, ésta es una pobre manera de entender el municipalismo, puesto que lo que interesa para defender esta idea, que para Castilla y León es una seña identitaria, son municipios fuertes, municipios que sean auténticos prestadores de los servicios que demandan los ciudadanos y no administraciones "fantasmas" que poco más que se dedican a la organización de las fiestas del Santo Patrón pues no tienen capacidad para ejecutar ningún otro servicio.

De oportunidad perdida ${ }^{24}$ calificamos nosotros a esta Ley en lo que respecta al objeto de este trabajo, ya que con ella no se conseguirá ninguna planta municipal que no sea la que conocemos y viene siendo una constante en nuestra historia constitucional.

Así las cosas, consideramos que la única solución que debe adoptarse si en realidad se quiere modificar la planta municipal es fusionar los municipios de manera obligatoria a la vista de que todas las medidas de fomento que se han dictado a lo largo de nuestra historia municipal han resultado un fracaso. Será una operación dolorosa e, incluso, traumática, pero necesaria si en realidad queremos hacer las reformas profundas que necesitamos.

El debate sobre nuestra planta municipal sigue abierto y la solución sigue sin ofrecerse más allá de las medidas coyunturales, como la expuesta, consecuencia de la situación de crisis que padecemos. Nuestro régimen local, desde sus cimientos, tiene que ser reformado.

\section{BIBLIOGRAFÍA}

ALONSO MAS, Ma José, “El nuevo régimen de las fusiones de municipios”, Reforma del régimen local: La Ley de Racionalización y Sostenibilidad de la Administración Local, veintitrés estudios, Navarra, 2014

BARRRANCO VELA, Rafael, Creación y segregación de municipios, Madrid, 1993.

\section{CALONGE VELÁZQUEZ, Antonio}

- “La planta municipal y las entidades locales menores en Castilla y León”, REAL, n 285, 2001

- “Organización territorial de la Comunidad Autónoma”, Derecho Público de Castilla y León, Valladolid, 2008.

CALONGE VELÁZQUEZ, Antonio y GONZÁLEZ DEL TESO, Teodosio, El Alcalde. Elección y destitución, Valladolid, 1997.

CARRILLO BARROSO, Ernesto, “La Administración municipal rural: los obstáculos de la reforma” REDA, n50, 1986.

\section{COSCULLUELA MONTANER, Luis}

- “Presentación”, Crisis económica y reforma del régimen local, Madrid, 2012.

- "Reforma de la Administración Local. Una oportunidad de modificar la planta municipal que no puede perderse", REDA, n 157, 2013.

ESCUIN PALOP, Catalina, “La alteración de términos municipales”, Tratado de Derecho Municipal, I, dir. Santiago MUÑOZ MACHADO, Madrid, 1988.

\section{FANLO LORAS, Antonio}

- “Estructura territorial”, Anuario del Gobierno Local, Madrid, 1995.

24 Parafraseando a COSCULLUELA MONTANER, L. (2013): nosotros entendemos que esta oportunidad que se presentaba para reformar la planta municipal se ha perdido de nuevo. 
- “Estructura territorial”, Anuario del Gobierno Local, Madrid, 1996.

FERNÁNDEZ RODRÍGUEZ, Tomás Ramón, Entre el derecho y la política (escritos dispersos de un jurista independiente), Madrid, 1987.

FLORES DOMíNGUEZ, Luis Enrique, “EI Proyecto de Ley de Racionalización y Sostenibilidad de la Administración Local. Novedades de la versión definitivamente aprobada”, Diario del Derecho Municipal, 11 de septiembre de 2013.

HEREDERO ORTIZ DE LA TABLA, Luis, "Cuestiones iniciales en torno al modelo de ordenación, servicios y gobierno del territorio de la Comunidad de Castilla y León de la Ley 7/2013, de 27 de diciembre”; Revista Jurídica de Castilla y León, $\mathrm{n}^{\circ}$ 34, 2014.

LÓPEZ ANDUEZA, Isaías, “Mancomunidades de municipios, servicios públicos y organización del territorio”, I Seminario Iberoamericano sobre Mancomunidades Municipales, Segovia, 1997.

ORDUÑA REBOLLO, Enrique, “Nuevas aportaciones sobre el mapa municipal español”, REAL, 2n²91, 2003.

REBOLLO PUIG, Manuel, "La crisis económica y la oportunidad de reducir el número de municipios”, Crisis económica y reforma del régimen local, Madrid, 2012.

SOSA WAGNER, Francisco y DE MIGUEL GARCÍA, Pedro, Creación, supresión y alteración de términos municipales. Madrid, 1987. 